\title{
Effective low-energy mixing procedure to develop high-fluidity cementitious pastes
}

Iman Ferdosian ${ }^{1}$, Aires Camões ${ }^{2}$

\author{
${ }^{1} \mathrm{PhD}$ Researcher, Center of Territory, Environment and Construction (CTAC), Department of Civil ngineering, Univer- \\ sity of Minho (4800-058 Guimarães, Portugal) \\ E-mail: iman_fn2007@yahoo.com \\ ${ }^{2}$ Assistant Professor, Center of Territory, Environment and Construction (CTAC), Department of Civil Engineering, \\ University of Minho (4800-058 Guimarães, Portugal) \\ E-mail: aires@ civil.uminho.pt
}

\begin{abstract}
Preparing a high fluidity paste is a major step in ultra-high performance concrete (UHPC) development with respect to its self-compacting ability as well as its ultra-high strength. In this regard, some experiments have been carried out in order to study various superplasticizer (SP) addition methods and times. Among these procedures, stepwise and delayed methods seem to be more efficient compared to direct addition of SP with or immediately after water addition. However, few studies regarding water addition time and method have been conducted since now. In this research work, the effects of water and SP addition methods on the fluidity of paste were investigated. The results demonstrated that stepwise and delayed water beside delayed SP addition remarkably reduce the flow time. This maximum fluidity was achieved after totally 15 minutes of mixing including 3 minutes after $70 \%$ of water addition to powder, as first-part water, 6 minutes after SP addition and finally an extra 6 minutes after second-part water which is $30 \%$ of the total water. Based on this procedure, the opportunity for developing self-compacting and durable UHPC could be accessible. Furthermore, using higher content of aggregates and supplementary cementitious materials would be possible due to higher fluidity of the paste which finally results in an eco-efficient UHPC.
\end{abstract}

Keywords: Ultra-high performance concrete (UHPC), Workability, Fluidity, Superplasticizer; Mixing method; Self-compacting, Concrete paste, Addition time, Eco-efficient.

\section{INTRODUCTION}

Ultra-high performance concrete (UHPC) is a new generation of durable and eco-efficient cementitious composites containing fibers, water to cement and water to binder ratio less than 0.25 and 0.2 respectively, an optimized graded granular component and high-range of water reducing agents, known as superplasticizer. UHPC must demonstrate enhanced properties in fresh and hardened state including self-compactness, compressive strength greater than $150 \mathrm{MPa}$ and $200 \mathrm{MPa}$ by application of normal curing and heat curing methods respectively beside extraordinary durability characteristics as the result of discontinues pore matrix $[1,2,3,4,5]$. According to the definition of mortar in "The European Guidelines for Self Compacting Concrete"[6], mortar is a fraction of concrete including paste and aggregates finer than $4 \mathrm{~mm}$ in size. Based on this definition, UHPC could be defined as a super high-tech cementitious mortar with extraordinary properties as mentioned above.

As a fundamental feature of UHPC, self-compactness is the ability of concrete to be casted just with gravity and without any extra compaction force with enough fluidity, homogeneity and stability even with the existence of dense reinforcement rebars [6]. In this regard, numerous researches have been investigated the influence of particle grading size and packing density enabling the particles in the paste or in the whole mixture slide down better on each other as a result of lower friction among the particles resulting in higher fluidity of pastes and concrete workability as well as higher compressive strength [7, 8, 9, 10, 11]. In other words, low packing density causes lower fluidity and workability which in turn results higher water demand and consequently higher cement content for the same level of workability and compressive strength [12]. 
With respect to all of the aforementioned considerations particularly low water to cement and binder ratio, as a prerequisite for obtaining ultra-high strength, enough fluidity would not be accessible without superplasticizer agents. In this regard, an efficient application of SP including its optimum dosage, the proper addition time to the materials and finally the mixing time of all ingredients plays an important role to maximize the SP effects on concrete paste resulting highest fluidity. Consequently, the water content for a definite target value of fluidity could be reduced which results in higher compressive strength and durability.

For better understanding of the chemical process of cementitious minerals dispersion by polycarboxylate-based superplasticizers, it was demonstrated that the plasticizing effect is attributed to the adsorption of anionic SP particles to cement particles, confined by $\mathrm{Ca}^{2+}$ as a positive layer from the cement dissolution in water [13]. According to this study, as time elapses, the $\mathrm{C}_{3} \mathrm{~S}$ and $\mathrm{C}_{2} \mathrm{~S}$ are consumed and $\mathrm{C}-\mathrm{S}-\mathrm{H}$ gels are gradually formed and the number of positive particles, adsorbing the SP chains, reduces. In this regard, the addition time of SP with respect to highest fluidity is during the first 15 minutes after adding water to cement and particularly between first 2 and 3 minutes [14]. Another recent experiment also confirms that stepwise and particularly delayed addition of SP, which mean adding SP in two stages and also not adding all the SP with water at the beginning respectively, could improve the flowability of UHPC by more than 25\% compared to direct addition of SP with or immediately after water addition [15]. Despite these studies, some experiments have been carried out just using stepwise addition of SP [16,17] and some with direct addition method [18].

\section{RESEARCH SIGNIFICANCE}

Limited studies were carried out on the effects of SP and particularly water addition time on concrete and especially the paste for UHPC which is highly sensitive to water and SP addition method. However it is right to say that the rheological behavior of full UHPC is different from its paste, since it contains other pozzolans and micro-sand, it is finally and highly dependent on the cement dispersion in the paste by superplasticizer since the cement content in UHPC is around 3 times more than silica fume in weight fraction[19]. It means that dispersion of cement particles is of great importance. However, as mentioned above, stepwise and delayed addition of SP may improve the flowability, the addition method of water has not been studied yet.

The findings of this paper help to improve the short and long-term performance of any concrete containing SP and low water/binder ratio, particularly UHPC, through enhancing the fluidizing effects of SP. In other words, the objective of this research is to promote the limited accessible knowledge regarding the mixing time after adding the water reducing agents and also stepwise water addition which both result in lower water content, higher workability, advanced strength, possibility of using higher aggregate content, which all lead to a more eco-efficient UHPC and pave the way towards sustainable construction.

\section{EXPERIMENTAL PROCEDURE}

According to the fact that the liquid SP is a solution of solid particles in water, which should be taken into account as a part of water to cement or binder ratio, first an appropriate quantity of SP was placed in oven at a temperature of $110^{\circ} \mathrm{C}$ for 72 hours until a constant weight was reached and the solid and water content of the SP could be attained. Afterwards, the saturation dosage of SP in which the flowing time is minimum was investigated for Portland cement I class $42.5 \mathrm{R}$ and $52.5 \mathrm{R}$ as the first phase of this research. This test method conforms to standard test method known as Marsh funnel test for viscosity of slurries [20, 21]. In order to prepare the slurry, in laboratory condition of $22^{\circ} \mathrm{C}$ and $50 \% \mathrm{RH}$, first the cement was poured in the mixer. The SP with different percentages of cement weight was mixed with the whole water, $35 \% \mathrm{w} / \mathrm{c}$, and added to the cement. Then all the constituents were mixed for 10 minutes. This test demonstrates that, the longer the time of flow the more viscose the slurry and less effective the SP.

In the second phase of the test, 3 general methods were studied. The first method includes watering the cement with $100 \%$ of the $0.35 \mathrm{w} / \mathrm{c}$ content, mixing for 3 minutes, adding SP and finally mixing for an extra 10 minutes. The second method is watering the cement with a fraction of the whole required water, in this case $60 \%$, mixing for 3 minutes, adding SP and mixing for another 4 minutes and finally adding the rest of $40 \%$ water and continuing the mixing for another 6 minutes. In the third general method, first $60 \%$ of water was poured in mixer containing cement, mixed for 3 minutes, SP was solved in the $40 \%$ of the rest of water and added to the mixture and the process continued for another 10 minutes. The all three methods are similar in such a way that the SP is mixed for 10 minutes after its introduction to the mix to reach a steadystate consistency. Moreover, in all the 3 methods based on the findings for highest SP efficiency [14,15], in which the effective time of SP addition is around 150 seconds after watering the cement, water and cement mixed for 3 minutes and then the SP was introduced. 
In the third phase, to fulfill the process of adding water and SP to the mix, $50 \%, 60 \%, 70 \%$ and $80 \%$ of the $0.35 \mathrm{w} / \mathrm{c}$ was introduced to cement as first-part water (FPW) and mixed for 3 minutes. Afterwards, with the same method for all the samples, SP was introduced and mixed for another 4 minutes and finally the rest of remained water poured in the mixer and mixed for another 6 minutes and again the Marsh cone test was performed to compare the outflow time of the pastes and find the best FPW with respect to outflow time.

After finding the best mixing procedure of watering and adding the SP to cement, the optimum required mixing time after adding SP to cement, which was fixed in the last tests in 4 minutes, with the aim of highest fluidity was investigated by altering the mixing time of SP, after its addition to the mix, from 2 minutes to 9 minutes. It should be noted that, the mixer used in this research is a mortar mixer according to EN 196-1[22]. Also, the low speed with planetary movement of $60 \mathrm{r} / \mathrm{min}$ was adopted.

\section{MATERIALS}

Type I Portland cement 42.5R and 52.5R were used. The Physical properties and chemical analysis are given in Table 1. A new generation of carboxylic ether polymer based SP with $18 \%$ of solid content was also used.

The SP (Table 2) is a brown liquid conforms to definitions and requirements for admixtures for use in concrete specified in European Standard EN 934-2 [23].

Table 1: Chemical and physical compositions of cement

\begin{tabular}{lcc}
\hline \multirow{2}{*}{ COMPONENTS } & \multicolumn{2}{c}{ WT\% } \\
& CEM I 42.5R & CEM I 52.5R \\
\hline \hline $\mathrm{SiO}_{2}$ & 19.79 & 20.61 \\
\hline $\mathrm{Al}_{2} \mathrm{O}_{3}$ & 4.37 & 4.89 \\
\hline $\mathrm{Fe}_{2} \mathrm{O}_{3}$ & 3.52 & 3.15 \\
\hline $\mathrm{CaO}$ & 63.09 & 63.52 \\
\hline $\mathrm{MgO}$ & 1.67 & 2.17 \\
\hline $\mathrm{SO}_{3}$ & 2.82 & 3.47 \\
\hline $\mathrm{Cl}^{-}$ & 0.04 & 0.04 \\
\hline $\mathrm{f}-\mathrm{CaO}$ & 1.18 & 1.30 \\
\hline $\mathrm{C}_{3} \mathrm{~S}$ & 65.9 & 58.84 \\
\hline $\mathrm{C}_{2} \mathrm{~S}$ & 4.56 & 11.19 \\
\hline $\mathrm{C}_{3} \mathrm{~A}$ & 5.63 & 7.64 \\
\hline $\mathrm{C}_{4} \mathrm{AF}$ & 10.7 & 9.58 \\
\hline $\mathrm{CS}$ & 4.79 & 5.9 \\
\hline loss of Ignition & 3.01 & 1.19 \\
\hline Blaine surface area $\left(\mathrm{cm}^{2} / \mathrm{g}\right)$ & 4228 & 4463 \\
\hline Specific gravity $\left(\mathrm{g} / \mathrm{cm}^{3}\right)$ & 3.11 & 3.15 \\
\hline \hline
\end{tabular}

Table 2: Technical characteristics of Superplasticizer

\begin{tabular}{|l|l|}
\hline RELATIVE DENSITY $\left(\mathbf{2 0}^{\circ} \mathrm{C}\right)$ & $1.05 \pm 0.02 \mathrm{~g} / \mathrm{cm}^{3}$ \\
\hline PH: & $7.3 \pm 1.5$ \\
\hline CHLORIDE ION CONTENT & $<0.1 \%$ \\
\hline SOLID CONTENT & $18 \%$ \\
\hline
\end{tabular}

\section{EXPERIMENTAL RESULTS AND DISCUSSION}

The optimum SP dosage was obtained for cement $42.5 \mathrm{R}$ and $52.5 \mathrm{R}$ as well. The outflow time for $300 \mathrm{~mL}$ of the paste and the SP dosage relationship are depicted in Fig. 1. The optimum dosage of liquid SP for cement $42.5 \mathrm{R}$ and $52.5 \mathrm{R}$ are $1.3 \%$ and $2.25 \%$ of the cement weight respectively corresponding to $0.23 \%$ and $0.41 \%$ solid particles in SP as well. It can clearly be seen that the general trend for both cements are the same. In other words, the viscosity deceases to the optimum dosage and after this point again increases and levels out with negligible fluctuations. Moreover, the viscosity of C 52.5R is generally higher than that of $\mathrm{C} 42.5 \mathrm{R}$ except the liquid SP dosage interval between $2 \%$ to $3 \%$. The higher viscosity of paste of cement $52.5 \mathrm{R}$ even 
with higher dosage of SP could be attributed to its finer particles and higher surface area. Due to the fact that the liquid SP is more viscous than the pure water, by passing the optimum dosage, in which most of cement particles are dispersed, and adding higher amount of liquid SP, with respect to its $82 \%$ of solvent water, the portion of pure water contributing in $35 \% \mathrm{w} / \mathrm{c}$ is reduced leading to higher viscosity and longer outflow time.

As a result, in both cases by passing the optimum SP content the viscosity increases sharply.

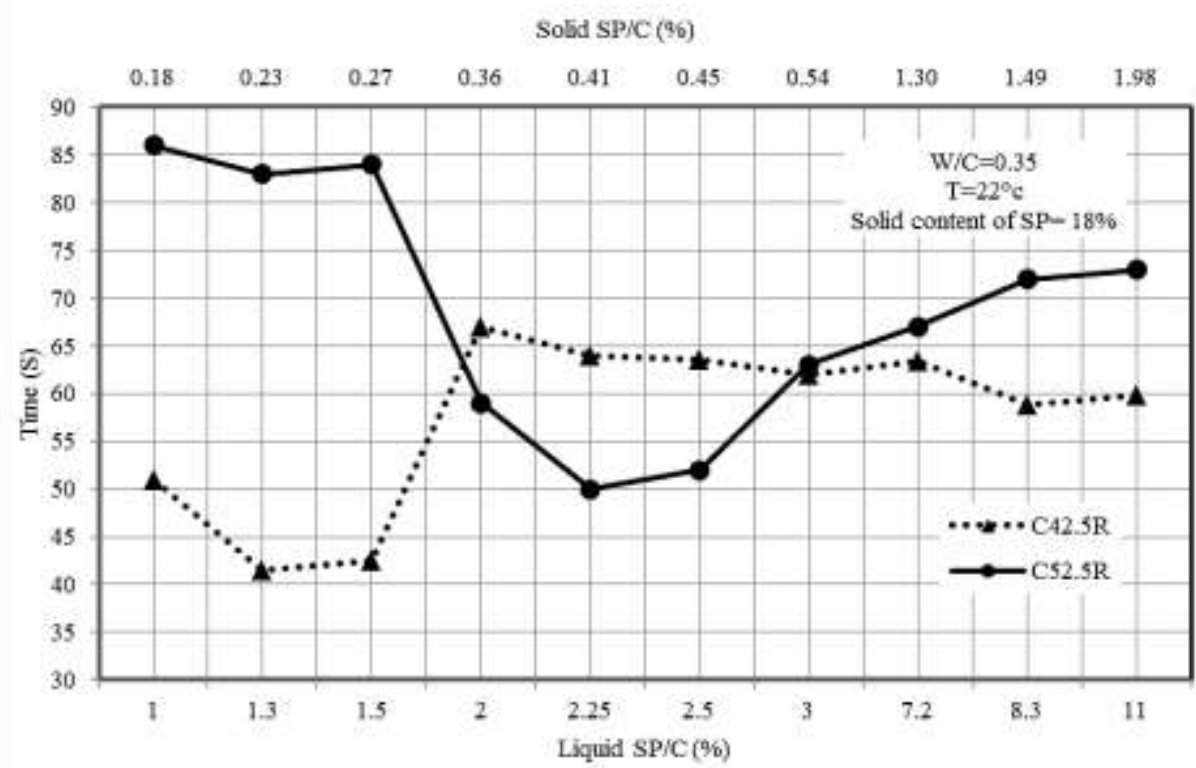

Figure 1: Effect of SP dosage on Marsh funnel time.

Based on the results obtained in this phase, $2.25 \%$ SP and $35 \%$ water in a fraction ratio to cement $52.5 \mathrm{R}$ weight were applied to perform the next phase. As described above, the second phase is to investigate the best method of watering the cement and adding the SP. It could be clearly seen in Fig. 2 that the test method M.2 reveals a huge difference in outflow time and fluidity. In fact as soon as a percentage of water introduces to the cement, cement particles dissolve in water and get ready to adsorb the anionic SP particles as a result of adsorption force between opposite charges which is a kind of chemical adsorption and goes beyond the aim of this research. Anyway, the SP disperses the cement particles and releases water. By now all these 3 methods are the same particularly the first and the third methods which shows almost the same results but in M.2 after the dispersion process of cement particles a percentage of water, which seems do not engaged in reaction with cement entirely, remain as a free water resulting a higher fluidizing effect and consequently lower outflow time thus proving its superiority among the other methods. These findings also are in agreement with the results reported in previous studies [14,15] demonstrating the effectiveness of delayed addition time of SP to cement. Furthermore, it can be understood that the stepwise and delayed water addition is also an efficient method with respect to higher fluidity as studied in this research work. 


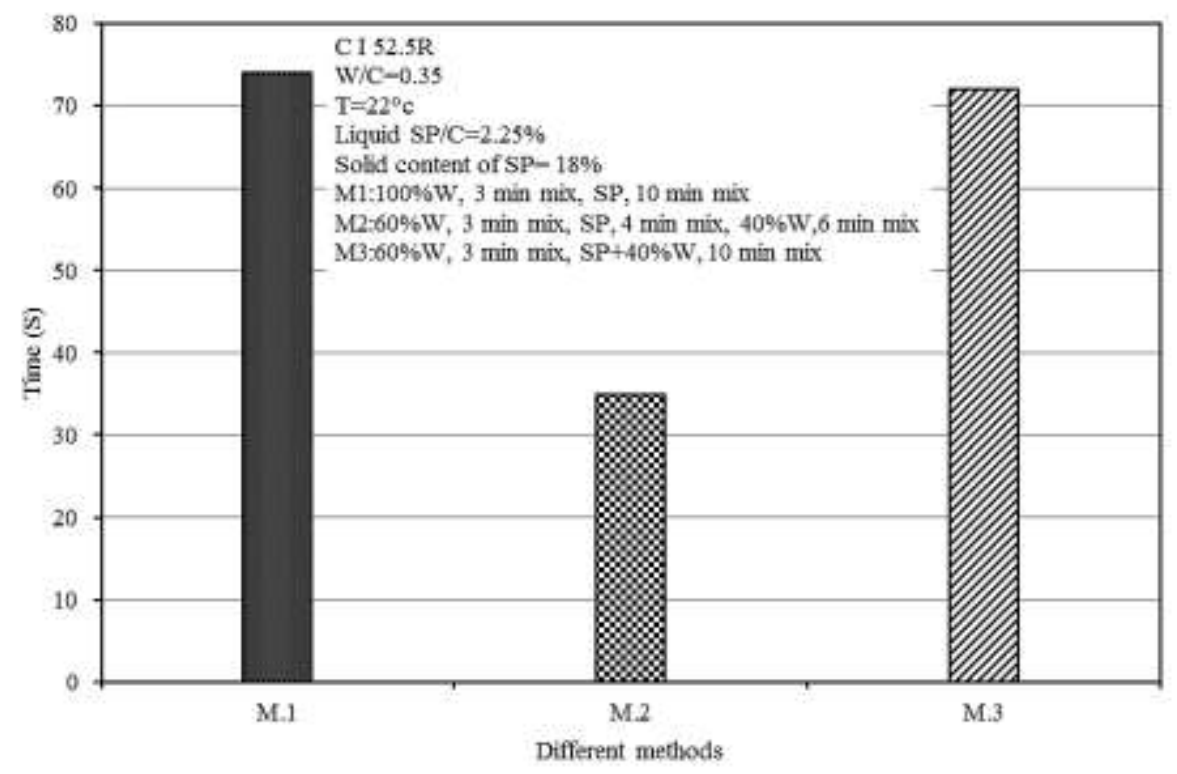

Figure 2: Effect of water and SP addition method on Marsh funnel time.

The next phase as mentioned in previous section is to optimize the detected method of watering the cement among different ratio of first-part water. As illustrated in Fig. 3, by increasing the amount of water, being mixed with cement to solve it and release the $\mathrm{Ca}^{2+}$ ions, from $50 \%$ to $70 \%$ the fluidizing effect of SP increases drastically. By passing the $70 \%$ of the whole water, i.e. $0.35 \mathrm{w} / \mathrm{c}$, the outflow time increases again.

The reason of higher viscosity for water quantities lower than $70 \%$ could be attributed to the lack of appropriate water to solve the cement particles and release the $\mathrm{Ca}^{2+}$ ions which adsorb the SP's chains. In other words, although enough SP content is accessible to disperse the cement particles, they cannot be charged positively and confined sufficiently with $\mathrm{Ca}^{2+}$ ions due to lack of water. On the other hand, for the first-part water fraction higher than $70 \%$, the lower efficiency of paste could be attributed to the lack of second-part water which could be remain free after the fluidizing effect of SP to improve its fluidity and accordingly reduce the outflow time.

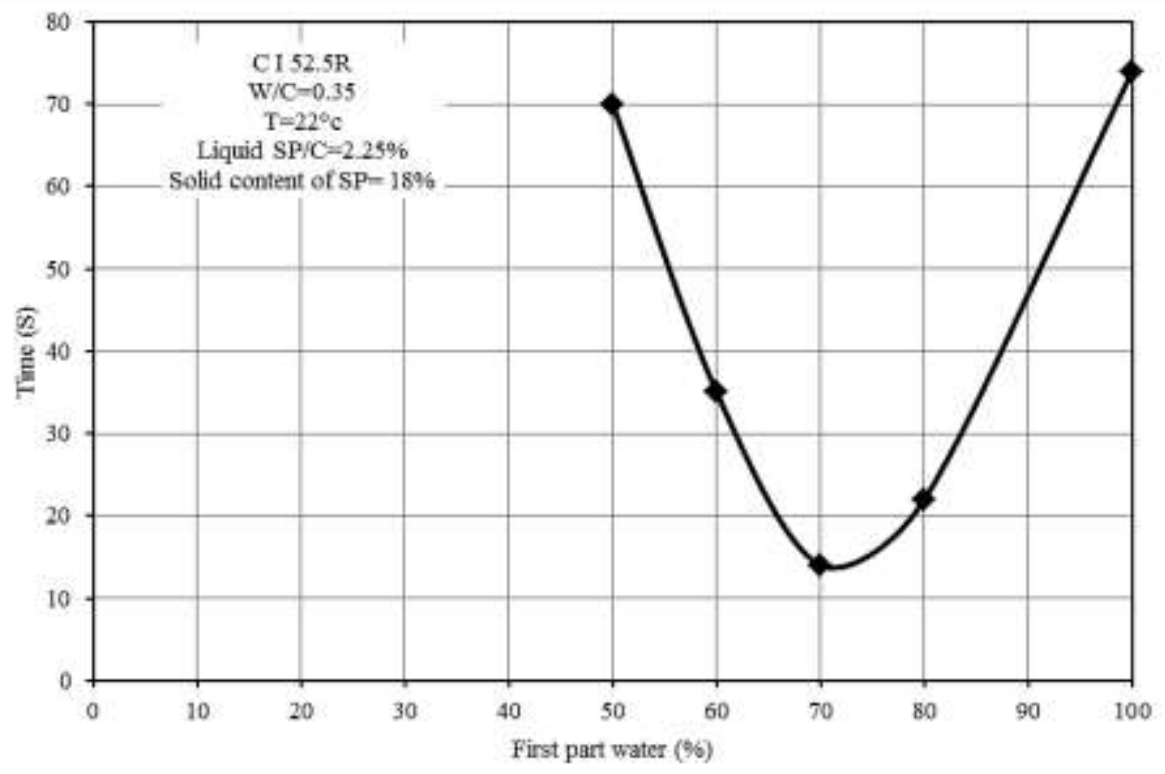

Figure 3: The relationship between the first-part water and Marsh funnel time. 
The final phase is to find out the minimum mixing time after SP addition to the wet cement. According to the obtained results in this research, these mixtures are all composed of $0.35 \mathrm{w} / \mathrm{c}$ and $2.25 \%$ SP/c. First $70 \%$ of water was introduced to the cement and mixed for 3 minutes. Consequently SP was added to the wet cement and mixed for 2, 4, 7 and 9 minutes. Finally the $30 \%$ of remained water poured in mixer and mixed for an extra 6 minutes. Based on Fig. 4 the results show that at least 4 minutes of mixing is obligatory after SP addition to the mix to be able to disperse the cement particles and release water.

Nevertheless, according to the improved apparent features of the paste such as less air bubbles, through visual observation, 6 minutes of mixing is suggested.

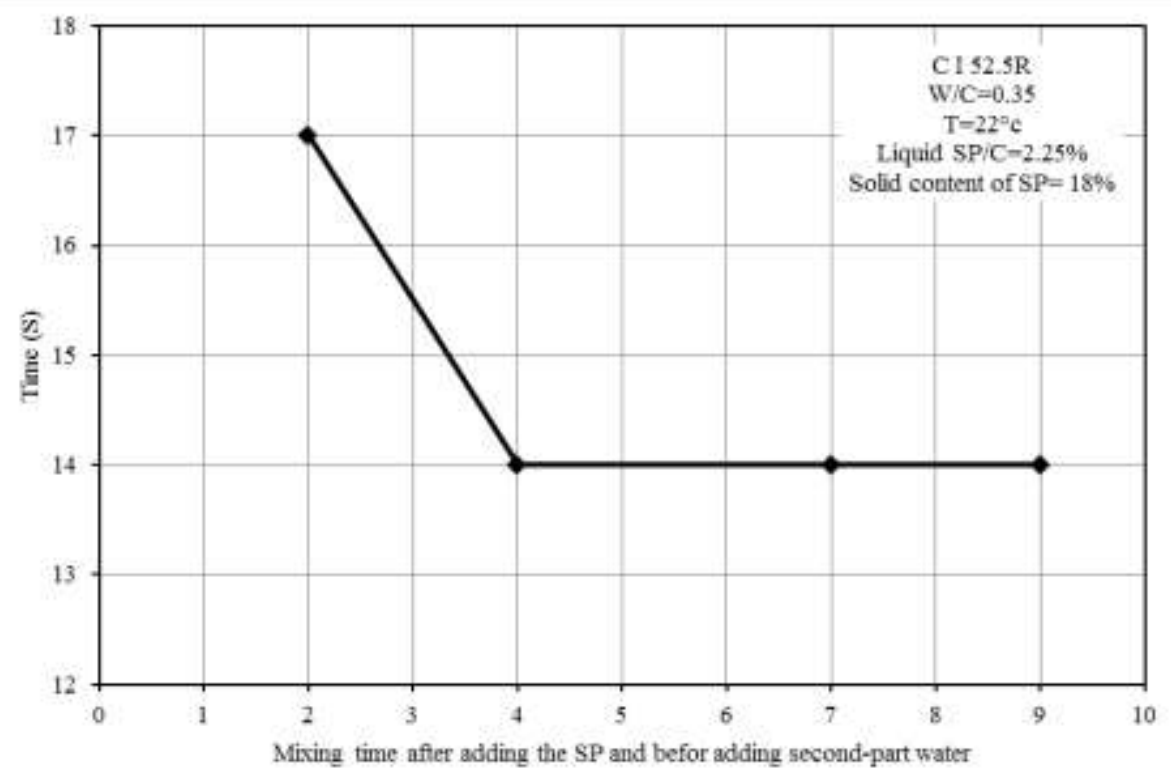

Figure 4: The effect of mixing time after adding SP on Marsh funnel time.

\section{CONCLUSIONS}

Effect of water and Superplasticizer addition time on paste preparation, which is of great importance for developing very low water/binder concretes namely self-compacting UHPC, was studied. It should be pointed out that the reported results such as addition time of water and SP could be changed slightly with any variation of the constituent materials such as cement type. It was found that the best fluidizing effect could be acquired after adding $70 \%$ of mixing water to the cementitious materials and mixing for 3 minutes followed by adding the optimum dosage of SP and mixing for at least 4 minutes, 6 minutes seems preferable based on visual assessment, and finally adding the remaining 30\% of water and blending for an extra 6 minutes to reach a steady-state consistency. However, the findings of this paper confirm the efficiency of delayed SP addition method, reported in previous studies $[14,15]$, they also demonstrate the effectiveness of delayed and stepwise water addition method as the main contribution of this paper. This provides the possibility of reducing the paste water content resulting in higher strength and durability or even, with the same w/c ratio, causes an improved workability or the possibility of increasing the aggregate content leading to a costeffective and eco-efficient UHPC.

\section{BIBLIOGRAPHY}

[1] RICHARD, P., CHEYREZY, M. “Composition of Reactive Powder Cconcretes”, Cement and Concrete Research, v. 25, n. 7, pp. 1501-1511, 1995.

[2] AÏTCIN, P.-C. "The Art and Science of High-Performance Concrete", Industria Italiana del Cemento, pp. 350-365, 1998.

[3] AFGC, Documents scientifiques et techniques-Ultra High Performance Fibre-Reinforced ConcretesInterim Recommendations, Paris, France, Association Française de Génie Civil (AFGC), 2002.

[4] RESPLENDINO, J. First recommendations for Ultra-High-Performance Concretes and examples of 
application, Kassel, Germany, Proceedings of the International Symposium on Ultra High Performance Concrete, 2004.

[5] GRAYBEAL, B. "Ultra-High Performance Concrete", Federal Highway Administration (FHWA), 2011.

[6] BIBM, CEMBUREAU, ERMCO, EFCA e EFNARC, "The European Guidelines for Self Compacting Concrete," 2005. [Online]. Available: http://www.civil.iitb.ac.in/cea/aakaar/docs/booklet.pdf. [Acesso em 21 7 2014].

[7] AFGC, Recommendations for use of Self-Compacting Concrete, Paris, France, Association Française de Génie Civil (AFGC) Publications, 2000.

[8] FERRARA, L., PARK, Y.-D., SHAH, S. P. "A method for mix-design of fiber-reinforced selfcompacting concrete”, Cement and Concrete Research, v. 37, p. 957-971, 2007.

[9] FAYED, M. E., OTTEN, L. Handbook of Powder Science \& Technology, New York, Chapman \& Hall, 1997.

[10] Brouwers, H., Radix, H. "Self-Compacting Concrete: Theoretical and experimental study", Cement and Concrete Research, v. 35, p. 2116 - 2136, 2005.

[11] F. De Larrard, "Concrete optimisation with regard to packing density and rheology," 3rd RILEM International Symposium on Rheology of Cement Suspensions such as Fresh concrete, France, 2009.

[12] GEISENHANSLÜKE, C., SCHMIDT, M. "Methods for Modelling and Calculation of High Density Packing for Cement and Fillers in UHPC", Proceedings of the International Symposium on Ultra High Performance Concrete, Kassel, Germany, 2004.

[13] YU, Y., LIU, J., RAN, Q., et al, "Interfacial Interaction Between Polycarboxylate-based Superplasticizer and Cement Component Minerals", Polymers \& Polymer Composites, v. 21, n. 5, pp. 299-305, 2013.

[14] HSU, K.-C., CHIU, J.-J., CHEN, S.-D. et al. Tseng, "Effect of addition time of a superplasticizer on cement adsorption and on concrete workability", Cement \& Concrete Composites, v. 21, pp. 425-430, 1999.

[15] TUE, N. V., MA, J., ORGASS, M. "Influence of addition method of suplerplasticizer on the properties of fresh UHPC," Proceedings of the Second International Symposium on Ultra High Performance Concrete, kassel, Germany, 2008.

[16] ROUGEAU, P., BORYS, B. "Ultra High Performance Concrete with ultrafine particles other than silica fume", In: Proceedings of the International Symposium on Ultra High Performance Concrete (UHPC), Kassel, Germany, 2004.

[17] SCHACHINGER, I., SCHUBERT, J., MAZANEC, O. "Effect of Mixing and Placement Methods on Fresh and Hardened Ultra High Performance Concrete (UHPC)", In: Proceedings of the International Symposium on Ultra High Performance Concrete, Kassel, Germany, 2004.

[18] EWERT, J., BUDELMANN, H., KRAUß, M. "Heat of Hydration and Hardening of Ultra High Performance Concrete (UHPC)", In: Second International Symposium on Ultra High Performance Concrete, Kassel, Germany, 2008.

[19] GRAYBEAL, B. A. "Material Property Characterization of Ultra-High Performance Concrete," FHWA, U.S., McLean, VA, 2006.

[20] ASTM D6910-04, Standard Test Method for Marsh Funnel Viscosity of Clay Construction Slurries, West Conshohocken, PA: ASTM International, 2004.

[21] FERRARIS, C., LARRARD, F. D., MARTYS, N. "Fresh concrete rheology: recent developments", In: Materials Science of Concrete VI, Amer. Cer. Soc. Ed., pp. 215-241, 2001.

[22] BS EN 196-1, Methods of testing cement- Part 1: Determination of strength, Brussels: EUROPEAN COMMITTEE FOR STANDARDIZATION, 1995.

[23] BS EN 934-2:2001 + A1:2004 + A2:2005 E, Admixtures for concrete, mortar and grout - Part 2: Concrete admixtures - Definitions, requirements, conformity, marking and labelling, Brussels: EUROPEAN COMMITTEE FOR STANDARDIZATION, 2001. 